\title{
Design and Analysis of Sheet Metal Control Arm
}

\author{
Bhushan Kumar $\mathbf{N}^{1}$, Dayakar ${ }^{2}$ \\ ${ }^{1}$ PG Scholar (Cad - Cam), MLRITM Dundigal, Hyderabad, Telangana, India \\ ${ }^{2}$ Associate Professor (Cad - Cam), MLRITM Dundigal, Hyderabad, Telangana, India
}

\begin{abstract}
Suspension system of an automobile plays an important role in ensuring the stability of the automobile. Although it has been achieved to a considerable extent, another major aspect of suspension system is passenger car is luxury. A lot of research is going on in this direction, which led to the development of independent suspension system. Control arm plays major role in independent suspension system. It is generally made of forged steel which has considerable disadvantages such as weight, cost etc. The project involves the development of sheet metal control arm, which has many advantages over forged metal. The component has been modeled using the curves extracted from workspace available in CATIA V5. This model is translated into IGES file, which is used for analysis.
\end{abstract}

Keywords: Control Arms, Suspension systems, CatiaV5, CAE model, Hypermesh.

\section{Introduction}

Control arm is the major part of the independent suspension system. It forms connection between the wheel hub and the automobile chassis. The main functions of control arm are:

- To form a rigid connection between the chassis and wheel hub, to which wheel is attached.

- It allows the wheel, the required degrees of freedom for proper steering and suspension abilities.

- It supports the spring and dampers, which form the major components for shock absorbing.

- To do these functions properly the control arm needs to sufficiently strong. Depending upon the position of the control arm, there are mainly two types of control arms.

- Upper and lower control arm. The springs and shock absorbers are supported between these arms, which prevents lateral movement of springs. Conventionally the control arms are manufactured by the process of forging the medium carbon steels, which are sufficiently strong.

- The Control Arm attaches to the Cradle/Frame at Two Points along with a ball joint position. These key points defines the Control Arm Shape.

- Position of the Control Arm is usually defined by Body Structures Group at the beginning of a new Program.

- The Arm should be as long as possible with in the packaging constraints.

Front suspensions are classified as Dependent and Independent suspensions. The most common dependent front suspension is the beam axle, which is used less and less in recent vehicles because of numerous disadvantages like large unsprung mass, and the packaging space, and considerable caster change. The most common types of front independent suspensions are the double wishbone suspension and the Macpherson strut. The double wishbone suspension also known as the double A-arm suspension has parallel lower and upper lateral control arms. The main advantage of the double wishbone is that the camber can be adjusted easily by varying the length of the lateral upper control arm such that it has a negative camber in jounce.

\subsection{Literature Survey}

Literature survey has been done by going through various papers presented by various professors are given below
Jong-Kyu Kim and Xue Gang Song [1] -Recently developed automotive components are getting lighter providing a higher fuel efficiency and performance. In this research, the shape of upper and lower control arm was determined by applying the optimization technology. This study considers the static strength in the optimization process. In this study, the kriging interpolation method is adopted to obtain the minimum weight satisfying the static strength constraint. Optimum design of static strength is obtained by the in-house program. MSC. Fatigue is used for assessment of the durability life, which is one of the most important criteria in automotive industry. In addition, the real experiments on $1 / 4$ car is conducted to validate the FEM analysis. At last, the correlation of each case about durability life is obtained.

Joel Hawley [2] -Control arms control the motion of the wheels so they're in line with the car's body. "Where the shock's job is to hold everything up, the control arm basically absorbs the road," Hawley says. "It's what gives way. It moves up and down so the tire can travel. When you hit a bump, the control arm compresses the weight and comes down on it. It keeps the bottom of your tire in its place. Auto experts say control arms connect the car's suspension to the actual vehicle frame. They are connected to the frame through a component called brushings, while they attach to the suspension through the ball joint. That allows the vehicle to turn its wheel and pivot, connecting the tire to the car's suspension.

M Bouzara [3] - Suspension control arms are important parts in a vehicle. Conventionally, these parts were made of steel, a heavy metal. Their geometry was designed by means of traditional engineering methods. Today we try to use the much lighter metal aluminum, to manufacture these parts instead of steel. Fuel consumption and emission of polluting gases are strongly dependent on car weight. So the automotive industry is looking at innovative technological processes making use of light alloys and new design methodologies. Cutting weight by using aluminum parts can

\subsection{Project Aim and Objectives}

- To Design Sheet metal control arm which meets customer requirement and standards. 


\section{International Journal of Science and Research (IJSR) \\ ISSN (Online): 2319-7064}

Index Copernicus Value (2013): 6.14 | Impact Factor (2014): 5.611

- The sheet metal control arm should meet Design for Manufacturability and assembly (DFMA).

- The Sheet metal control arm should meet stiffness and strength analysis as forged control arm.

- The weight of the sheet metal control arm should be less compared to the forged control arm.

- The design of the Sheet metal control arm should be simple and it should be used for re-design in Catia.

\subsection{Project Scope}

- This study will investigate the difference of forged control arm and sheet metal control arm.

- Based on observations design improvements will be made in terms of shape, size and material based on design modification objectives.

- The study will focus on existing design performance, advantage and limitations.

- Sheet metal control arm design will be tested using FEM software and compared with forged control arm results.

\section{Design Method}

\subsection{Basic Design of Forging Control Arm}

\section{a) Forging Operation}

Forging is the operation where the metal is heated and then a force is applied to manipulate the metal in such way that the required final shape is obtained. This is the oldest of the metal working processes.

\section{b) Forging types}

- Smith forging: this is the traditional forging operation done openly or in open dies by the village black smith or modern shop floor by manual hammering or by power hammers.

- Drop forging: This operation done in closed impression dies by means of the drop hammer .Here the force shaping the component is applied in a series of blows.

- Machine forging: Unlike the drop or press forging where the material drawn out, in machine forging, the material is upset to get the desired shape.

\section{c) Advantages}

- Uniformity of qualities for parts subjected to high stress and loads.

- Speed of production, Close tolerances

\section{d) Disadvantages}

- High tool cost

- High tool maintenance

- No core holes \& limitations in size and shape.

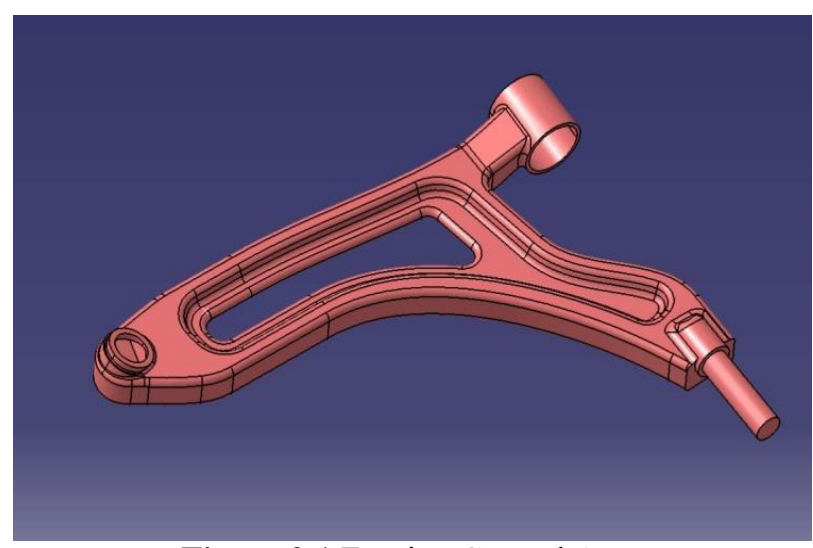

Figure 2.1 Forging Control Arm

Weight of the Forging Control Arm: $7.5 \mathrm{Kgs}$

Material Type: Micro Steel Alloy (C45)

\subsection{Sheet Metal Control Arm Design}

\section{a) Sheet Metal Operation:}

The sheet metal operation basically involves the process of press working consists of shearing and then plastically working the metal to the desired finished shape and the size through a few quick strokes under heavy loads. Most control arms are stampings. Stampings are cheap, fairly durable if properly designed and manufactured, and can be fairly easily shaped. As with all types of design, it is good to get a manufacturing engineer involved in control arm design early, as he can decide if building a certain type is feasible.

\section{b) Advantages}

- It is one the cheapest and fastest way of complete manufacture of a component.

\section{c) Disadvantages}

- Sheet metal operations are generally performed on the sheets of thickness less than $5 \mathrm{~mm}$.

d) Design considerations:

- Space

- Strength

- Weight

- Manufacturing feasibility Cost.

- Try to design a LH/RH common control arm

- Position of the bushing and ball joint determines the shape of the arm

- Simple and aesthetically pleasing design should be a preference.

\subsection{Solid Modeling}

Solid modeling is a crucial step in the design process. It allows the user to create a three dimensional picture of their design without physically creating a prototype or spending excessive time drawing sketches by hand. The solid modeling software used for this project was called CATIA. It

was created by Dassault Systems who also created other engineering software programs such as Solid Works. The basic process of solid modeling in CATIA involves drawing a two-dimensional sketch and then extruding or removing 


\section{International Journal of Science and Research (IJSR) \\ ISSN (Online): 2319-7064}

Index Copernicus Value (2013): 6.14 | Impact Factor (2014): 5.611

material in a third direction. There are also various secondary functions that are also very helpful. The fillet replaces a sharp edge with a rounded corner. This function is especially useful in removing stress concentrations. Another important function for our project was the shell function.

\subsection{Proposal-1}

\section{a) Design of Upper Panel}

The Upper panel is the most important component in Control Arm design. The main mountings such as Steering Gear mounts, Shock Absorber mounts and Ball joints will be mounted on the Upper Panel. The upper panel has to design in such a way that it should meet all the clearance requirements as specified.

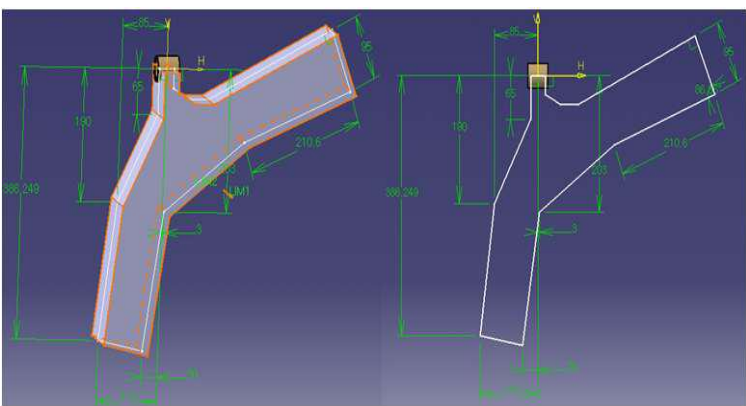

Figure 2.2: Sketch and Extrusion

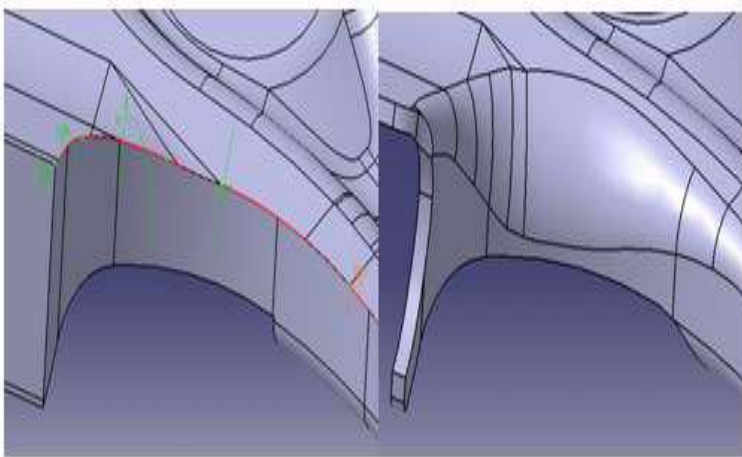

Figure 2.3: Variable Fillet Radius

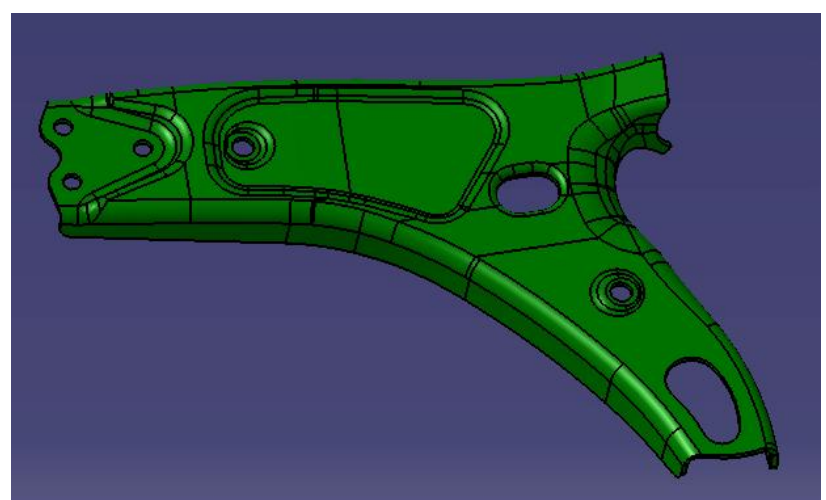

Figure 2.4: Shell Operation

\section{b) Design of Reinforcement-1}

Reinforcements are added in the control arm design to attain good stiffness and strength. Due to the common problem of the lower control arm cracking when driven under harsh conditions, the fitment of this reinforcement is strongly recommended.

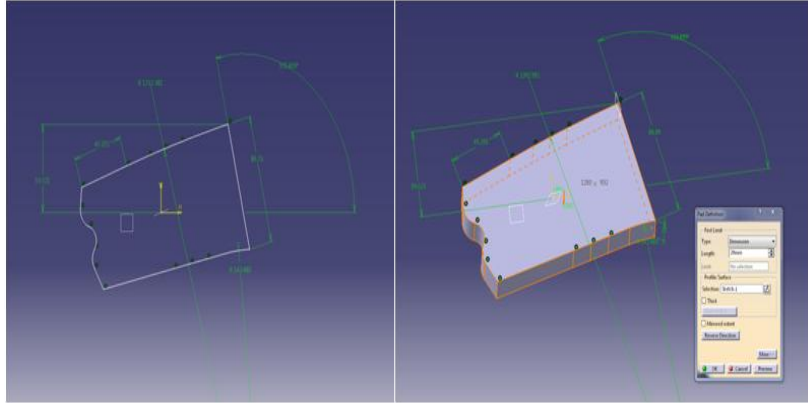

Figure 2.5: Sketch and Extrusion

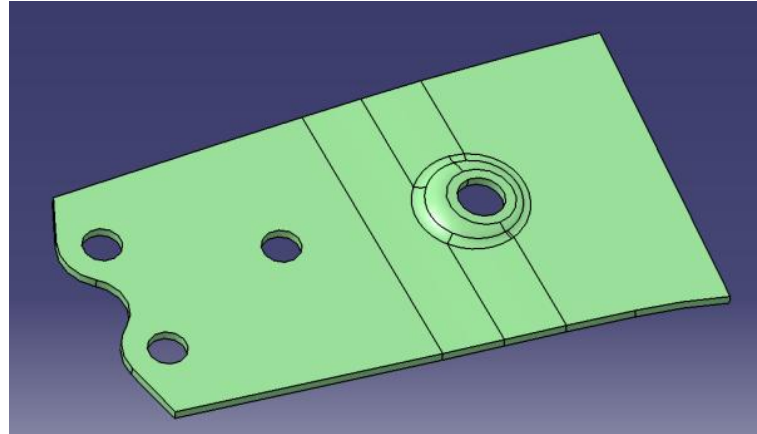

Figure 2.6: Shell Operation

\section{c) Design of Reinforcement-2}

While designing both reinforcements we have to check the mountings should not be miss-match and the fitment of the reinforcements should match perfectly with the upper panel for assembly conditions. The design of the reinforcements should be simple and must be easy for re-design.

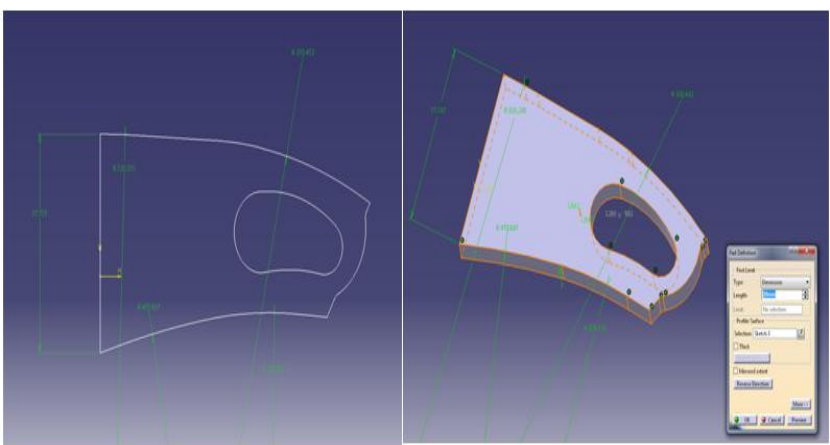

Figure 2.7 Sketch and Extrusion

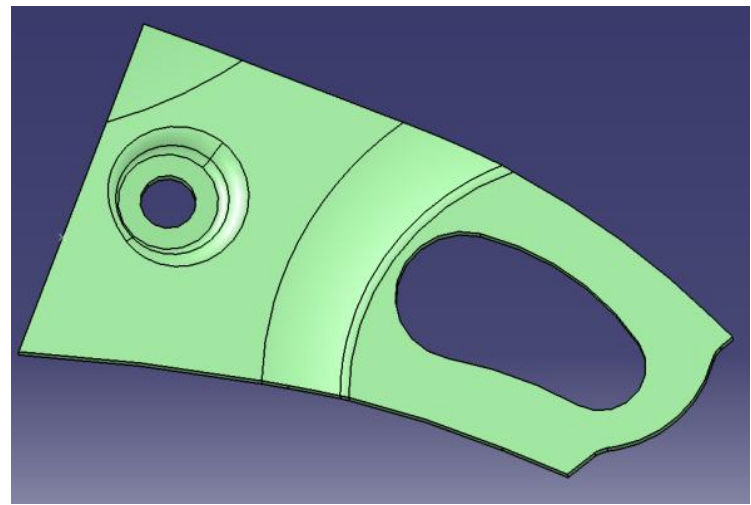

Figure 2.8 Shell Operation 


\section{International Journal of Science and Research (IJSR) \\ ISSN (Online): 2319-7064}

Index Copernicus Value (2013): 6.14 | Impact Factor (2014): 5.611

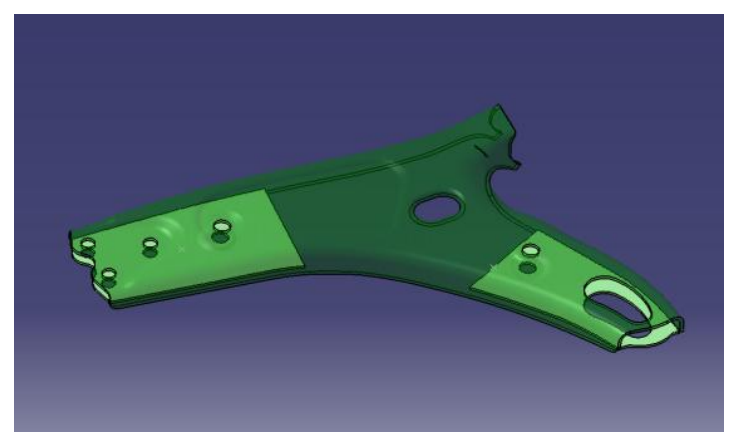

Figure 2.9: Reinforcements Fitment to the upper panel

d) Proposal-1 Bill of Material

Table 2.1 Prsp-1 BOM

\begin{tabular}{|c|c|c|c|c|}
\hline Part Name & Quantity & $\begin{array}{l}\text { Guage } \\
\text { (mm) }\end{array}$ & Material Spec. & Weight (Kg) \\
\hline Upper Panel & 1 & 3 & FB600 & 1.39 \\
\hline Reinf Lwr_ 1 & 1 & 2.8 & $\mathrm{FB} 600$ & 0.2 \\
\hline Reinf Lwr 2 & 1 & 2.8 & $\mathrm{FB} 600$ & 0.2 \\
\hline- & - & - & - & - \\
\hline Spike Forging & 1 & 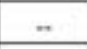 & $\mathrm{C} 45$ & 0.56 \\
\hline Ball Joint Forging & 1 & - & $\mathrm{CAS}$ & 0.58 \\
\hline Sleeve & 1 & - & SAPH440 & 0.18 \\
\hline & & & Total Weight & 3.11 \\
\hline
\end{tabular}

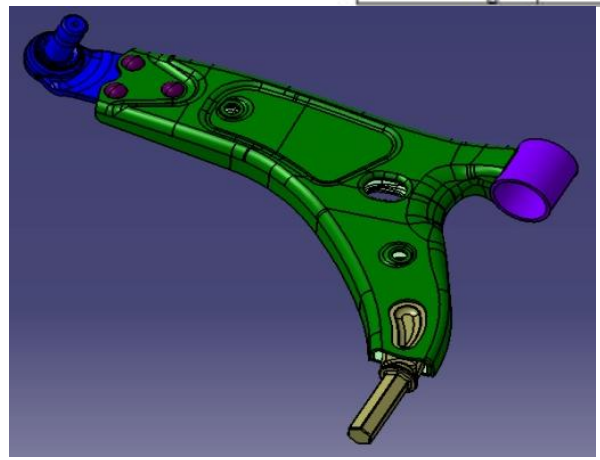

Figure 2.10: Complete Assembly Control Arm Proposal-1

\subsection{Proposal-2}

a) Design Modification of Upper Panel

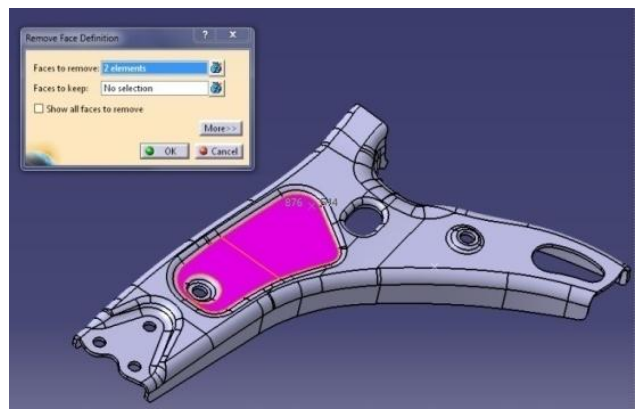

Figure 2.11 Removing the Pocket feature in Upper Panel

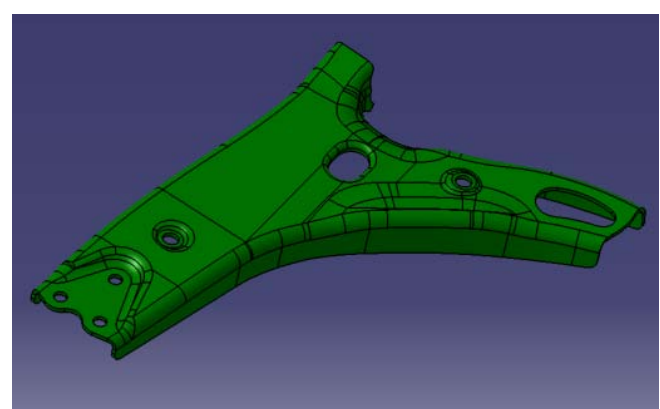

Figure 2.12: Shell Operation

b) Design Modification of Reinforcement

In the proposal-2 one reinforcement is implemented. By implementing single reinforcement we can reduce the manufacturing cost and assembly cost.

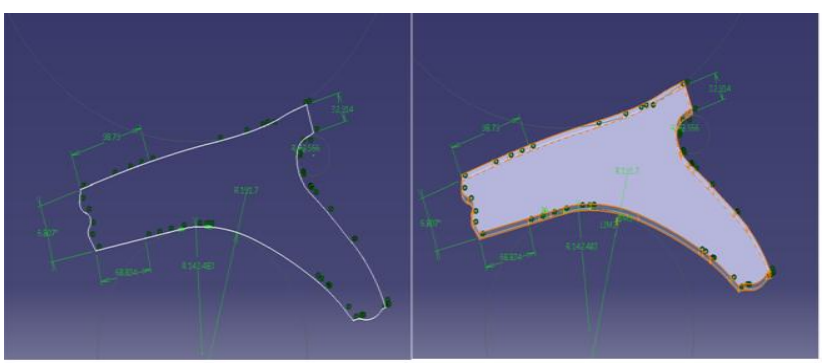

Figure 2.13: Sketch and Extrusion

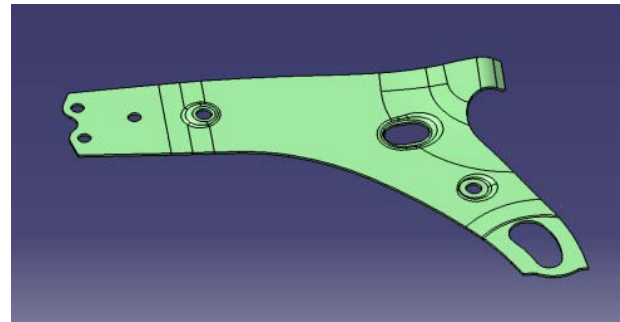

Figure 2.14: Shell Operation

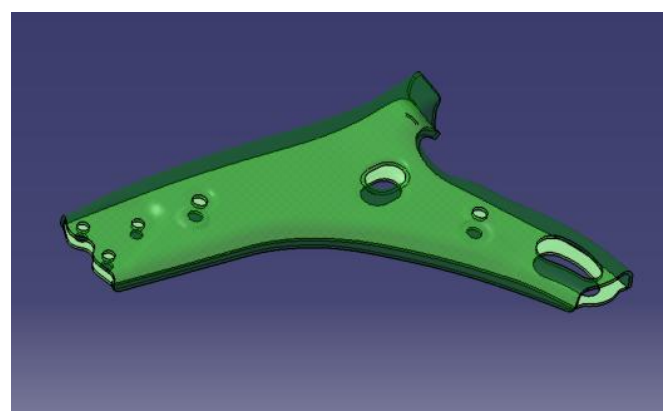

Figure 2.15: Reinforcement Fitment to the upper panel

c) Proposal-2 Bill of Material

Table 2.2: Prsp-1 BOM

\begin{tabular}{|c|c|c|c|c|}
\hline Part Name & Quantity & Guage (mm) & Material Spec. & Weight (Ke) \\
\hline Upper Panel & 1 & 3 & FB600 & 1.6 \\
\hline Reinf Lwr & 1 & 2.8 & $\mathrm{FB} 600$ & 0.2 \\
\hline 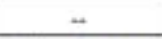 & - & - & - & - \\
\hline Spike Forging & 1 & - & $\mathrm{CA5}$ & 0.56 \\
\hline $\begin{array}{l}\text { Ball Joint } \\
\text { Forging }\end{array}$ & 1 & - & C45 & 0.58 \\
\hline Sleeve & 1 & - & SAPH440 & 0.18 \\
\hline & & & Total Weight & 3.12 \\
\hline
\end{tabular}

Volume 4 Issue 11, November 2015 


\section{International Journal of Science and Research (IJSR) \\ ISSN (Online): 2319-7064}

Index Copernicus Value (2013): 6.14 | Impact Factor (2014): 5.611

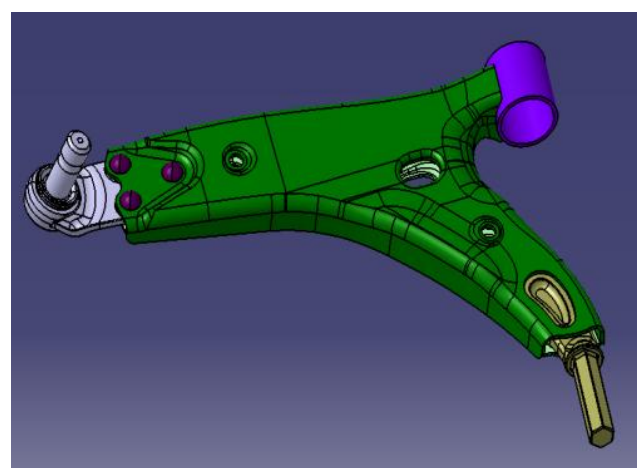

Figure 2.16: Complete Assembly of Control Arm Proposal-2

\section{Finite Element Method}

\subsection{FEA Introduction}

After the geometry of the part is modeled, it must be analyzed for stress analysis. Simple shapes are easily calculated through traditional methods on pen and paper. Parts which have a complex shape are not easily calculated in the traditional manner and a different approach must be taken, The Finite Element Method.

\subsection{Forging Control Arm Meshing}

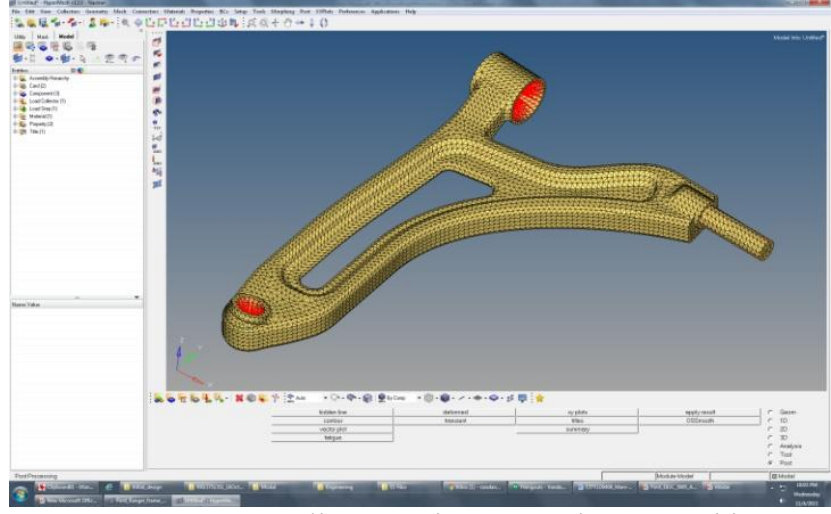

Figure 3.1: Base line Forging control arm meshing

\subsection{Material Properties}

\section{Steel C45 (Mat.No.1.0503,DIN C45,AISI 1045)}

a) Chemical Composition (in weight \%)

Carbon $0.46 \%$

Silicon $0.40 \%$

Manganese $0.65 \%$

Chromium $0.40 \%$

Molybdenum $0.10 \%$

Nickel $0.40 \%$

b) Mechanical Properties in Normalized Condition

\begin{tabular}{|l|l|l|l|l|}
\hline $\begin{array}{c}\text { Diameter } \\
\mathrm{d} \\
(\mathrm{mm})\end{array}$ & $\begin{array}{c}\text { Thickness } \\
\mathrm{t}\end{array}$ & $\begin{array}{c}0.2 \% \text { proof } \\
\text { stress } \\
\left(\mathrm{m} / \mathrm{mm}^{2}\right)\end{array}$ & $\begin{array}{c}\text { Tensile } \\
\text { strength } \\
\left(\mathrm{N} / \mathrm{mm}^{2}\right)\end{array}$ & $\begin{array}{c}\text { Elongation } \\
\mathrm{A}_{5} \\
(\%)\end{array}$ \\
\hline$<16$ & $<16$ & $\mathrm{~min} .390$ & $\mathrm{~min} .620$ & $\mathrm{~min} .14$ \\
\hline$<17-100$ & $<16<=100$ & $\min .305$ & $\min .305$ & min. 16 \\
\hline$<101-250$ & $<100<250$ & $\min .275$ & min. 560 & min. 16 \\
\hline
\end{tabular}

3.4 Sheet Metal Control Arm -Proposal 1 Meshing

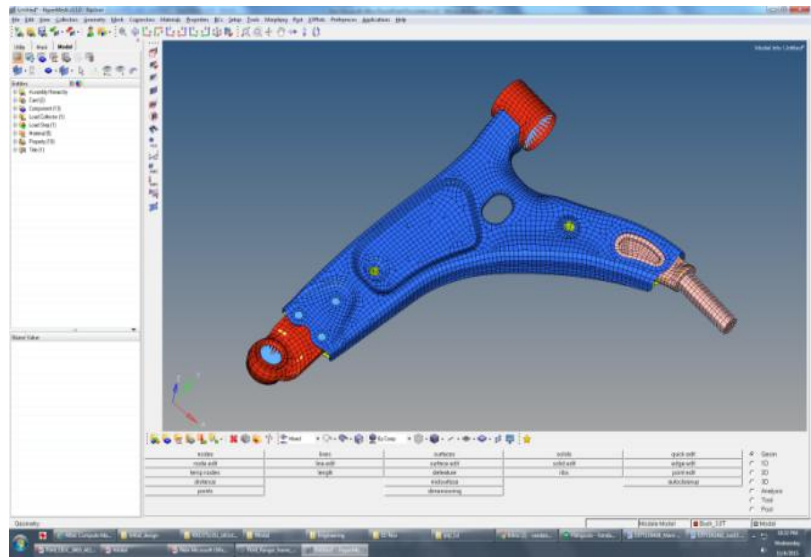

Figure 3.2: Proposal-1 control arm meshing

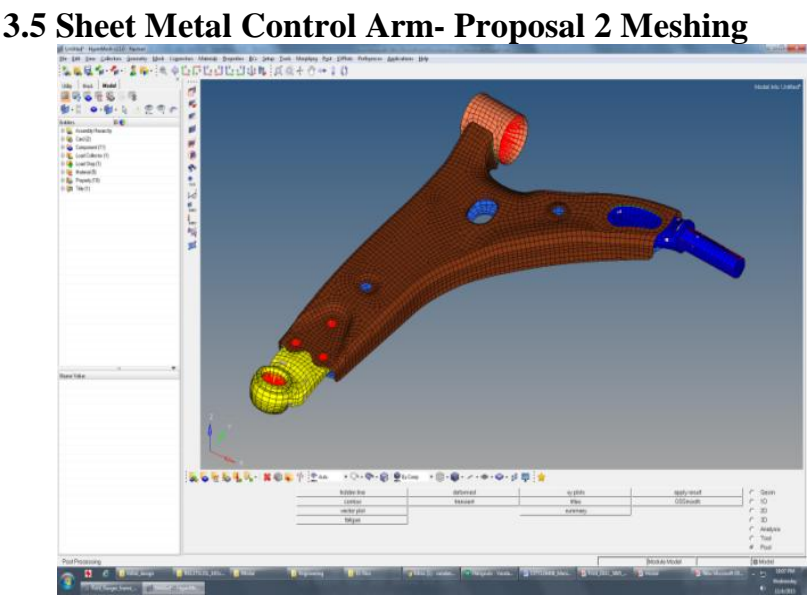

Figure 3.3: Proposal-2 control arm meshing

\subsection{Material Properties}

\section{FB590- Ferritic-Bainitic (FB) Steel}

FB steels sometimes are utilized to meet specific customer application requirements that require Stretch Flangeable (SF) or High Hole Expansion (HHE) capabilities for improved edge stretch capability.

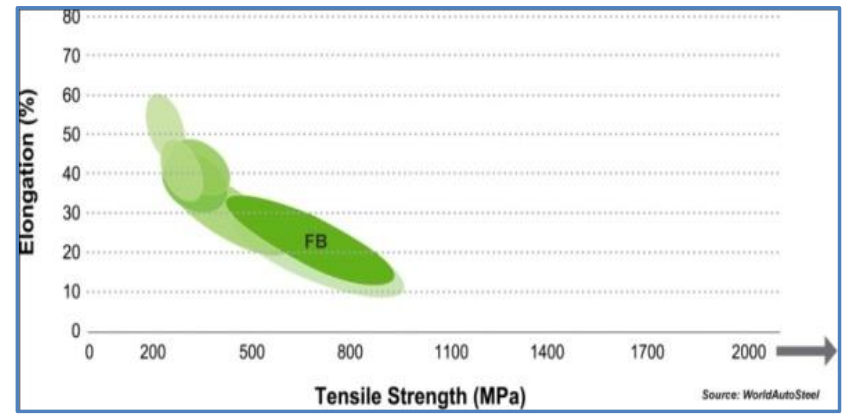

Graph 3.1 FB600 Material Elongation vs. Tensile Strength

a) Chemical composition:

Copper $0.05 \%$

Manganese $2.00 \%$

Silicon $0.80 \%$

b) Mechanical Properties:

Yield Strength (0.2\% Offset) 480-600 Mpa

Tensile Strength 590-670Mpa 


\section{International Journal of Science and Research (IJSR) \\ ISSN (Online): 2319-7064}

Index Copernicus Value (2013): 6.14 | Impact Factor (2014): 5.611

Elongation $\geq 16 \mathrm{~mm}$

Poisson's ratio $(\sqrt{ })$ 0.27-3.0

3.7 Model Analysis Results

Table 3.1 Model Analysis Results

\begin{tabular}{|c|c|c|c|c|}
\hline Model & Target & $\begin{array}{c}\text { Base line } \\
\text { Frequency }(\mathrm{Hz})\end{array}$ & $\begin{array}{c}\text { Proposal-1 } \\
\text { Frequency(tz) }\end{array}$ & $\begin{array}{l}\text { Proposal-2 } \\
\text { Frequency(Hz) }\end{array}$ \\
\hline Model-7 & \multirow{6}{*}{$\begin{array}{l}\text { Frequency Values Should } \\
\text { not be in between } 80 \mathrm{Ht} \text { to } \\
\qquad 300 \mathrm{~Hz}\end{array}$} & $616.56 \mathrm{~Hz}$ & $324.06 \mathrm{~Hz}$ & $32406 \mathrm{~Hz}$ \\
\hline Model-8 & & $764.06 \mathrm{~Hz}$ & $383.64 \mathrm{~Hz}$ & $383.64 \mathrm{~Hz}$ \\
\hline Model-9 & & $851.21 \mathrm{~Hz}$ & $511.79 \mathrm{~Hz}$ & $51179 \mathrm{~Hz}$ \\
\hline Model-10 & & $1160.63 \mathrm{~Hz}$ & $636.23 \mathrm{~Hz}$ & $636.23 \mathrm{~Hz}$ \\
\hline Model-11 & & $1437.01 \mathrm{~Hz}$ & $956.74 \mathrm{~Hz}$ & $956.74 \mathrm{~Hz}$ \\
\hline Model-12 & & $1656.75 \mathrm{~Hz}$ & $996.18 \mathrm{~Hz}$ & $996.18 \mathrm{~Hz}$ \\
\hline
\end{tabular}

\subsection{Stiffness Analysis}

\section{a) Base Line}

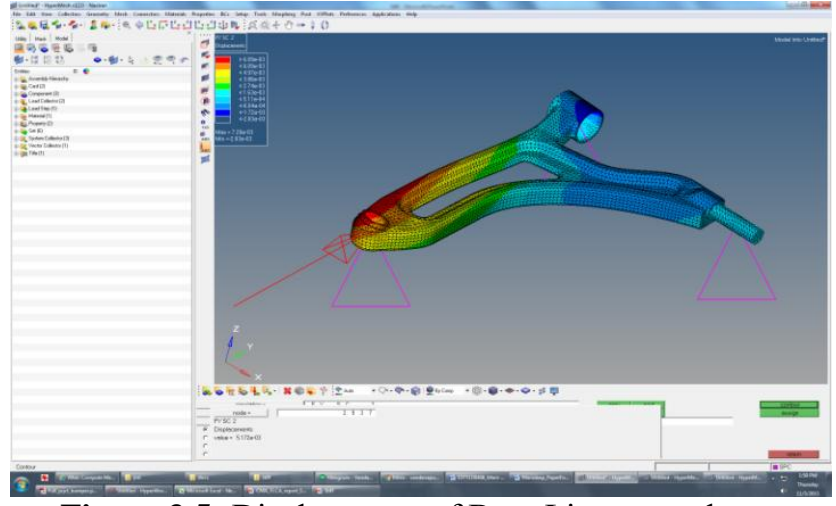

Figure 3.5: Displacement of Base Line control arm

\section{b) Proposal 1}

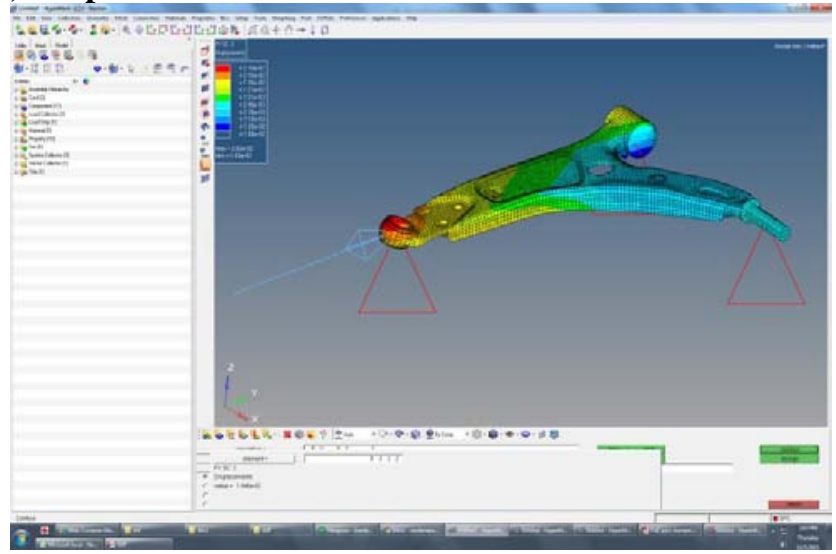

Figure 3.6: Displacement of Proposal-1

c) Proposal 2

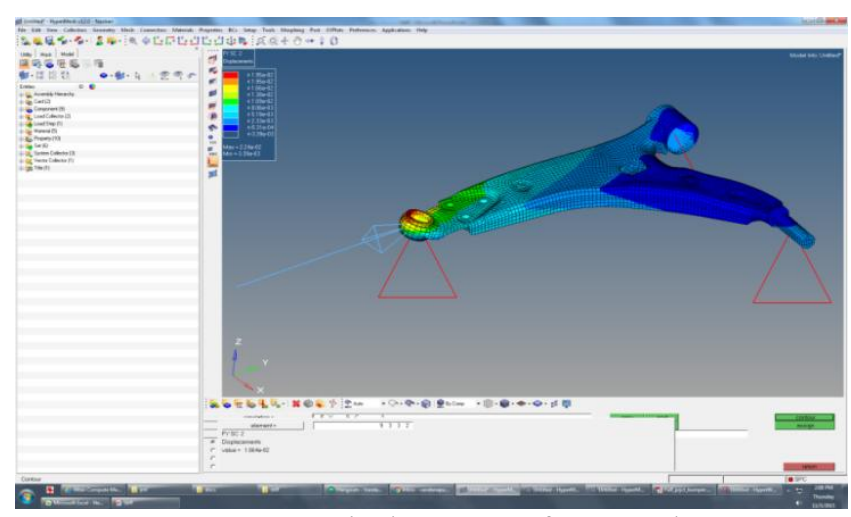

Figure 3.7: Displacement of Proposal-2

3.8.1 Stiffness Analysis Results

Table 3.2 Model Analysis Results

\begin{tabular}{|c|c|c|c|c|c|}
\hline PRPS & $\begin{array}{c}\text { Target } \\
\mathrm{KN} / \mathrm{mm}\end{array}$ & Load & Displacement & stiff in N/mm & Stiff in KN/mm \\
\hline & & & & & \\
\hline Base & 70 & 1000 & 0.005172 & 193348.80 & 193.35 \\
\hline & & & & & \\
\hline PRPS 1 & 70 & 1000 & 0.019990 & 50025.01 & 50.03 \\
\hline & & & & & \\
\hline PRPS 2 & 70 & 1000 & 0.011570 & 86430.42 & 86.43 \\
\hline
\end{tabular}

Stiffness Results

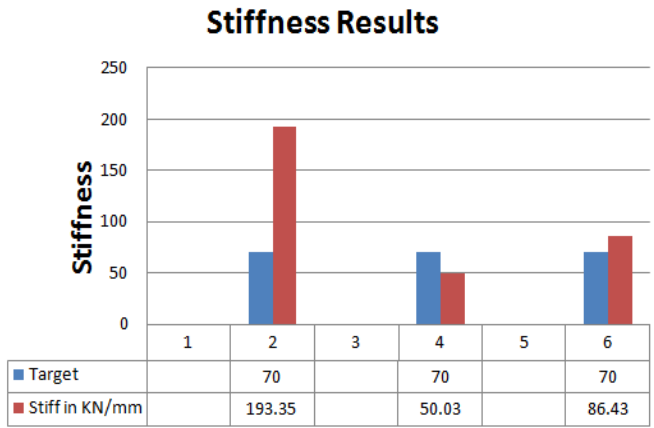

Graph 3.2 Stiffness Analysis Results

3.9 Strength Analysis

a) Base Line

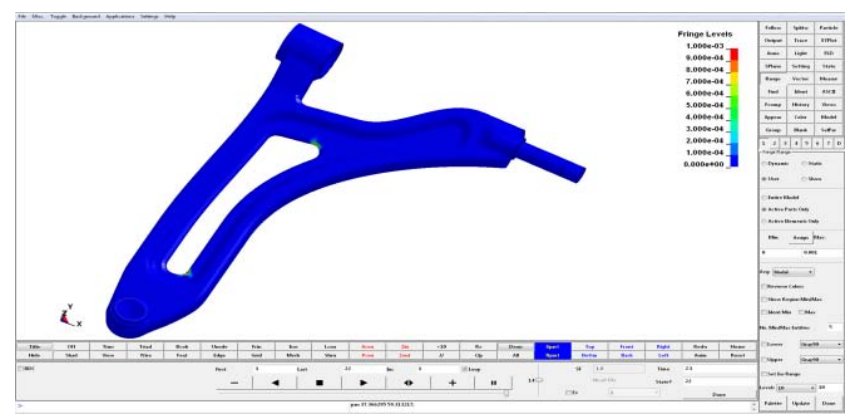

Figure 3.8: Plastic Strain of Baseline Control Arm 


\section{International Journal of Science and Research (IJSR) \\ ISSN (Online): 2319-7064}

Index Copernicus Value (2013): 6.14 | Impact Factor (2014): 5.611

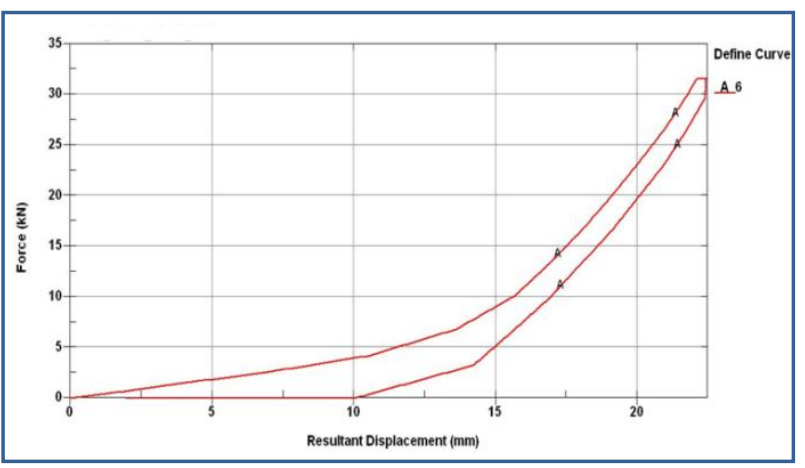

Graph 3.3: Force vs. Displacement

\section{b) Proposal 1}

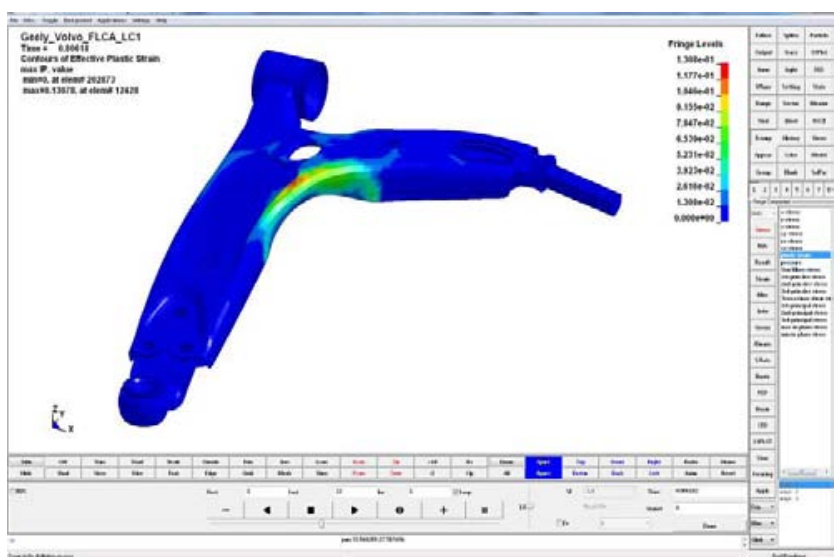

Figure 3.9: Plastic Strain of Prps-1 Sheet metal Control Arm

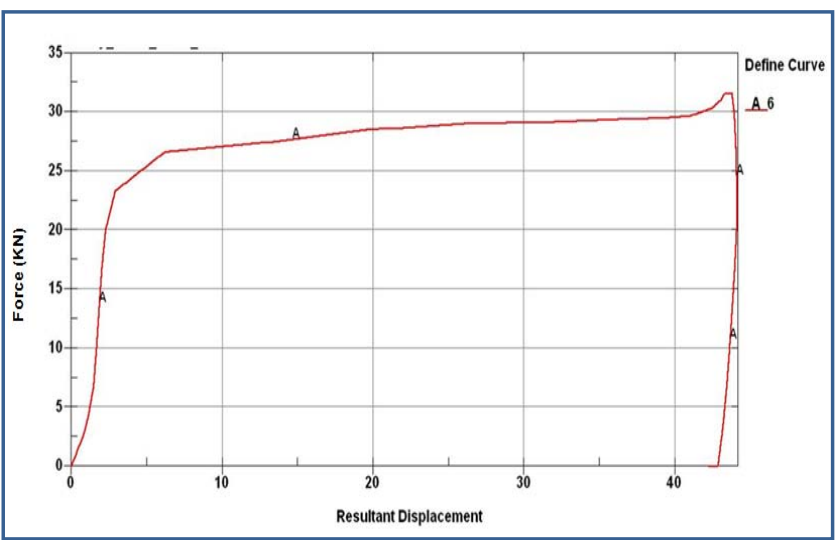

Graph 3.4: Force vs. Displacement

\section{c) Proposal 2}

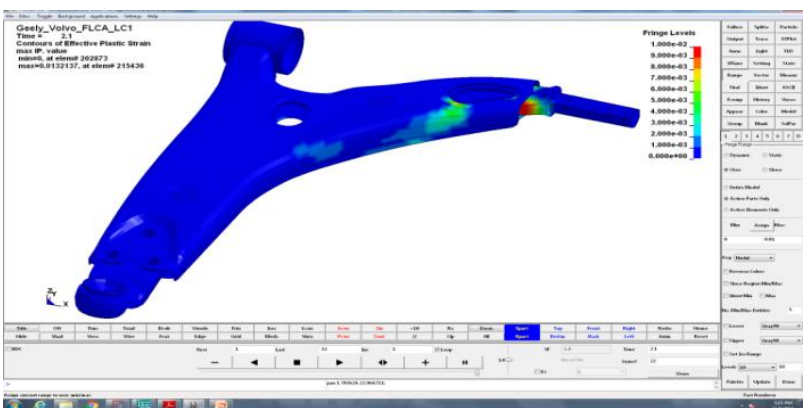

Figure 3.10: Plastic Strain of Prps-1 Sheet metal Control Arm

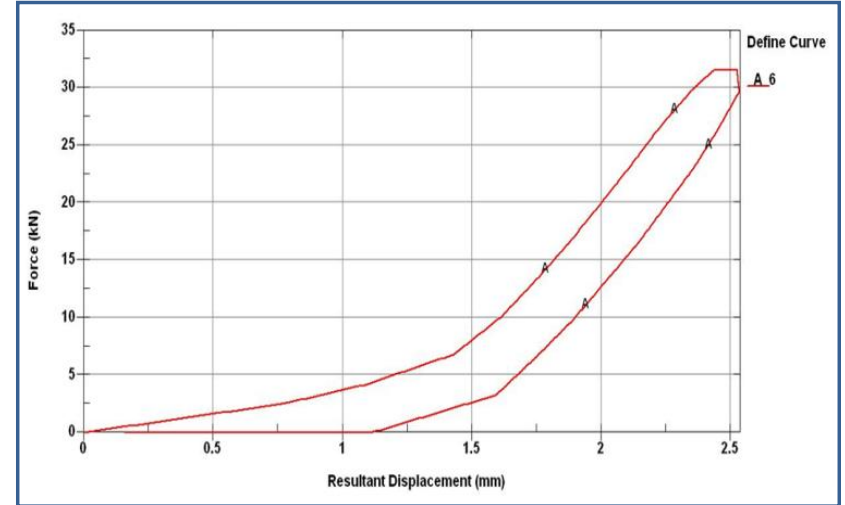

Graph 3.5: Force vs. Displacement

\subsubsection{Strength Analysis Results}

a) Permanent set at Ball Joint

Table 3.3 Strength Analysis Results

\begin{tabular}{|c|c|c|c|c|}
\hline Target (mm) & Load case & Baseline & Proposal-1 & Proposal-2 \\
\hline 2 & BIP & 1.8 & 44 & 1.5 \\
\hline
\end{tabular}

The OEM constraints for permanent set is less than or equal to $2 \mathrm{~mm}$.

b) Plastic Strain

Table 3.4 Strain Results

\begin{tabular}{|c|c|c|c|}
\hline Target (\%) & Baseline & Proposal-1 & Proposal-2 \\
\hline 2 & 1.6 & 13 & 1.3 \\
\hline
\end{tabular}

\section{Observations}

From the design $\&$ analysis results it is observed that

- The weight of the sheet metal control arm is decreased compared to the forged control arm.

- From the stiffness and strength analysis it is observed that proposal-1 doesn't meet customer targets.

- Proposal-2 meets the stiffness and strength requirements. .

\section{Conclusions}

From design and analysis data, it is observed that

- The weight of the component is decreased by $58 \%$ i.e., the weight of the forged model is $7.5 \mathrm{~kg}$ and the weight of the Proposal-2 sheet metal model is $3.12 \mathrm{~kg}$.

- Ease of manufacturing. The sheet metal operations are simple and cheap when compared to the forged operations.

- Ball joints of the different standards can be used by varying the size of the hole by changing the piercing hole.

- The cost of the component is reduced to a considerable extent as the raw material used for sheet metal component is very cheap than that used for forged component.

- The results obtained from analysis infer that the sheet metal satisfies all the design considerations. The stress obtained for different load conditions are within limits. Stiffness observed to be satisfactory. 


\section{International Journal of Science and Research (IJSR) \\ ISSN (Online): 2319-7064}

Index Copernicus Value (2013): 6.14 | Impact Factor (2014): 5.611

- The sheet metal control arms shows high strength, good fatigue properties, good aptitude for hole flanging, weld ability.

Hence, the sheet metal control arm is more beneficial than the forged control arm

\section{References}

[1] Jain, K.K., R.B. Asthana. Automobile Engineering. London: Tata McGraw-Hill.

[2] "Design For Manufacturing (DFM) Guidelines Engineers Edge." Engineers Edge - Design, Engineering \& Manufacturing Solutions. Web. 09 June 2011.

[3] Heinz Heisler, "Modern Automobile Engineering", McGraw Hill publishers, 2001.

[4] J.Reimpell, H.Stoll, J.W.Betzler, "The Automotive Chassis”, SAE International, 2nd edition, 2001.

[5] P.N. Rao, "Manufacturing Technology"TATA McGraw Hill publishing company, 7th edition, 1987, pp 261-284. 